\title{
Antidepressant Therapy has Restored Albumin Conformation in Anxious Depression
}

\author{
Uzbekov $\mathbf{M}^{1 *}$, Syrejshchikova $\mathrm{T}^{2}$, Smolina $\mathrm{N}^{3}$, Maximova $\mathrm{N}^{4}$, Shikhov $\mathrm{S}^{3}$ and Brilliantova $\mathrm{V}^{5}$ \\ ${ }^{1}$ Head of the Laboratory of Brain Pathology, Russia \\ ${ }^{2}$ Senior researcher, laboratory of high energy, Russia \\ ${ }^{3}$ Senior researcher, Laboratory of Brain Pathology, Russia \\ ${ }^{4}$ Senior researcher, department of affective disorders, Russia \\ ${ }_{5}^{5}$ Junior researcher, Laboratory of Brain Pathology, Russia
}

*Corresponding author: Uzbekov M G, Head of the Laboratory of Brain Pathology, Moscow, Russia

\begin{tabular}{|c|c|}
\hline ARTICLE INFO & ABSTRACT \\
\hline Received: 幽 September 23, 2019 & Citation: Uzbekov M, Syrejshchikova $\mathrm{T}$, Smolina N, Maximova N, Shikhov $\mathrm{S}$, et al. \\
\hline Published: 慧 October 03, 2019 & $\begin{array}{l}\text { Antidepressant Therapy has Restored Albumin Conformation in Anxious Depression. } \\
\text { Biomed J Sci \& Tech Res 21(4)-2019. BJSTR. MS.ID.003647. }\end{array}$ \\
\hline
\end{tabular}

\section{Short Communication}

Recent data indicate that different pathological conditions are followed not only by the disturbances in protein concentration but also by changes of their physicochemical properties which are manifested, in particular, in the conformational changes. Such changes can be detected using several biophysical methods: crystallographic measurements, nuclear magnetic spectroscopy, nonradioactive energy transfer, equilibrium dialysis, ultrafiltration, and fluorescence spectroscopy. The last method is the most informative one. Specific molecular fluorescence probes played an important role in such studies. The probes represent analogs of natural ligands and drugs and serve as markers of the binding sites of the protein molecule. The fluorescence of the probes is extremely sensitive to minor variations in the conformation and physicochemical properties of proteins related to functional disorders [1]. The knowledge of the molecular processes related to the conformational changes of the albumin molecule caused by the mental diseases can be used for the improvement of diagnostic procedures, the estimation of severity of disease, prediction of consequences and evaluate the efficacy of therapy, especially psychopharmacotherapy. The time resolved (subnanosecond) fluorescence spectroscopy, which allows the measurements of minor local changes and the selective study of the albumin binding sites is the most convenient method [1].

\section{Subjects and Methods}

There were investigated 10 patients with anxious depression. The patient's state according to ICD-10 criteria [tenth edition, clinical modification (ICD-10-CM] (World Health Organization, 2015) [2] was defined as a depressive episode as an independent disease (F32.1) and together with recurrent depressive disease (F33.1). The presence of anxiety together with depression was the main indication for the inclusion to the investigation. The clinical severity of the illness was assessed using the Hamilton Rating Scale for depression (HAM-D) (21 items) and the Hamilton Rating Scale for anxiety (HAM-A). These patients were investigated in dynamics of antidepressant pharmacotherapy (tianeptine in a dose of 37.5 $\mathrm{mg}$ /day): at admission and after 2 weeks of therapy. Control group consists of 10 healthy volunteers. Investigation was performed in accordance with the permission of the local ethical committee of Moscow Research Institute of Psychiatry (N 16, 13.03.2017). Nanosecond laser time resolved fluorescence spectroscopy with CAPIDAN (dimethylaminonaphthalic acid N-carboxyphenylimide) fluorescent probe was used for the investigation of albumin conformation. The fluorescence decay of CAPIDAN probe bound to serum albumin was measured in nano- and pico-second ranges using a laser device developed at the Lebedev Physical Institute. Fluorescence was excited by a rapid laser flash (7 x 10-10 s) at 405 
$\mathrm{nm}$, emission wavelength $-535 \mathrm{~nm}$. The measurement process and the processing of experimental data were automated by using a personal computer based on the AMD Sempron processor (Timo Harp and FluoFit programs, Picoquant) [3].

\section{Results and Discussion}

The theory of albumin - CAPIDAN interaction was described earlier in the journal "Laser Physics" [4]. But the limitation of that work was that there were investigated and compared only patients before and after the treatment without control group. In present paper we have performed the complete investigation. The experiments with the human serum albumin samples have revealed different effects of the ionic composition of the solution on the albumin structure. We have measured the fluorescence decay curves at three values of the ionic strength. The best and most stable results were obtained for serum with ionic strength of about $0.6 \mathrm{M}$ ( $\mathrm{KCl}$ ions). There were revealed 3 binding sites on albumin molecule in controls with the amplitudes (A1, A2 and A3) corresponding to the three fluorescent decay times of 9, 3 and 1 nanoseconds. The most pronounced data were received at binding site with amplitude A1. In this paper we shall described only results that we have received investigating biding center of 9 nanoseconds because the 2 other sites have given very near results. The significance of differences for controls and patients with anxious depression before therapy was $\mathrm{p}<0.02$ according to Wilcoxon test to independent samples (Figure 1). The values of A1 for controls and patients before therapy were $52.2 \pm 1.4$ and $42.5 \pm 2.2$ arbitrary units (a.u.), respectively. After the 2 weeks of pharmacotherapy differences of values of amplitude $\mathrm{A} 1$ between controls and treated patients were insignificant ( $p=0.24$ ): $52.2 \pm 1.4$ and $48.8 \pm 2.4$ a.u., respectively. It means that antidepressant pharmacotherapy promotes the recovery of conformational state of albumin molecule in patients with anxious depression (Figure 1).

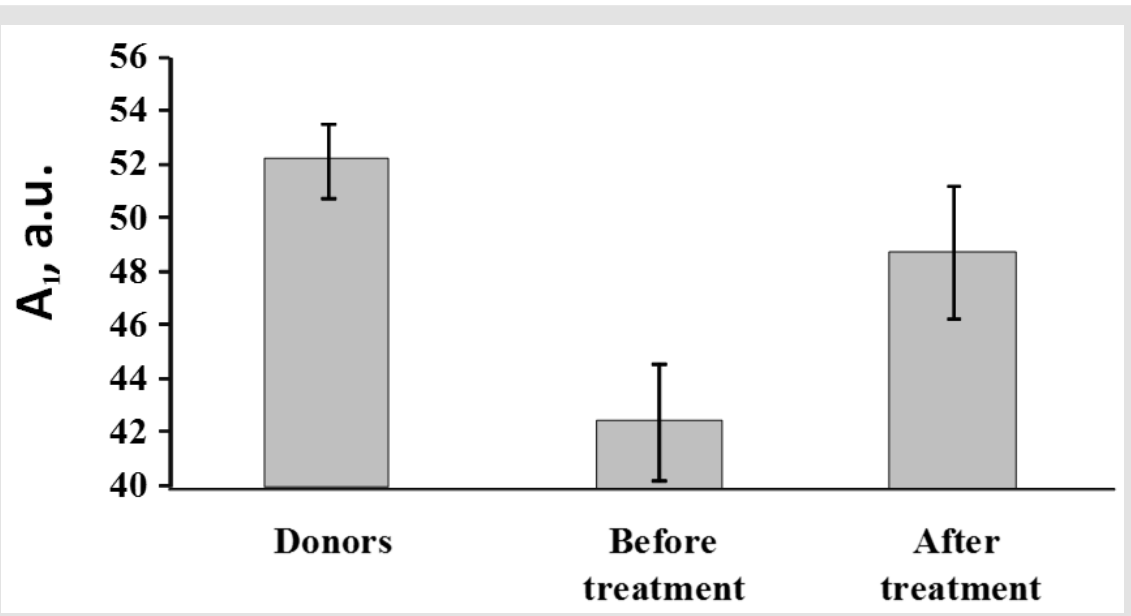

Figure 1: Mean values of amplitude A1 fluorescence decay of CAPIDAN probe in controls and patients with anxious depression before and after antidepressant therapy $(\mathrm{M} \pm \mathrm{m}) . \mathrm{pH}=7.4$; Ionic strength $=0.6$. au - arbitrary units.

\section{Conclusion}

In this paper it was shown that anxious depression is followed by conformational changes of albumin molecule that can affect different albumin functions. Antidepressant therapy using tianeptine restores conformation of albumin molecule that coincided with remission of patient's status [5]. We think that albumin conformational parameters can serve as a biomarker of the efficacy of pharmacotherapy.

\section{References}

1. (2015) World Health Organization, International Classification of Diseases and Related Problems. (10 ${ }^{\text {th }}$ Edi.) Clinical Modification, WHO, Geneva, Switzerland.
2. Syrejshchikova TI, Smolina NV, Brilliantova VV, Uzbekov MG, Dobretsov GE (2017) Albumin Binding-Site Alteration in Melancholic Depression under Pharmacotherapy: Recording with the Use of ubnanosecond Fluorescence Spectroscopy. Biophysics 62(2): 286-290.

3. Syrejshchikova NI, Smolina NV, Uzbekov MG, Dobretsov GE, Kalinina VV (2015) Disturbances in serum albumin conformation in patients with melancholic depression. SS Korsakov Journal of neurology and psychiatry 115(Suppl 2): 47-50.

4. Syrejshchikova NI, Gryzunov Yu A, Smolina NV, Komar AA, Uzbekov MG, et al. (2010) Subnanosecond Fluorescence spectroscopy of human serum albumin as a method to estimate the efficacy of the depression therapy. Laser Physics 20 (5): 1074-1078.

5. Uzbekov M, Misionzhnik E, Maximova N, Vertogradova O (2006) Biochemical profile in patients with anxious depression under the treatment with serotonergic antidepressants with different mechanisms of action. Human Psychopharmacology: Clinical and Experimental 21(2): 109-115. 


\section{ISSN: 2574-1241}

DOI: 10.26717/BJSTR.2019.21.003647

Uzbekov M. Biomed J Sci \& Tech Res

(C) (P) This work is licensed under Creative

Submission Link: https://biomedres.us/submit-manuscript.php

$\begin{array}{ll}\text { BIOMEDICAL } & \text { Assets of Publishing with us } \\ \text { RESEARCHES } & \text { - Global archiving of articles } \\ & \text { - Immediate, unrestricted online access } \\ \end{array}$

